\title{
Osteoarthritis of knees: the disease burden in Hong Kong and means to alleviate it
}

\author{
WH Yuen *, FHKCOS, FHKAM (Orthopaedic Surgery) \\ Department of Orthopaedics and Traumatology, Queen Elizabeth Hospital, Jordan, Hong Kong \\ * yuenwh@ha.org.hk
}

Hong Kong Med J 2014;20:5-6

DOI: 10.12809/hkmj134191

It is a well-known fact that most developed cities are facing the problems of ageing, and Hong Kong is no exception. It is predicted that $21 \%$ of Hong Kong inhabitants will be aged 65 years or above in year 2024 , as compared to $13 \%$ in the year $2009 .{ }^{1}$ In other words, within 10 years, one in every five citizens of Hong Kong will be seniors.

Knee osteoarthritis (OA) is one of the most common degenerative diseases, and is one of the commonest causes of disability in the elderly. The prevalence of knee OA in Chinese men is similar to that in Caucasian men, but is significantly higher among Chinese women than Caucasian women.,3 The Beijing Osteoarthritis Study showed that in the population group aged 60 years or more, the prevalence of radiographic knee OA was $42.8 \%$ in women and $21.5 \%$ in men, and symptomatic knee OA occurred in $15.0 \%$ of women and $5.6 \%$ of men. ${ }^{3}$ Hence, it is expected that in our ageing population, the knee OA will generate more and more impact on the health care system.

Conservative treatment for knee OA includes lifestyle modification, weight reduction, use of walking aids, physiotherapy, and analgesics. Exercise interventions under the supervision by physiotherapists are recommended for knee OA. ${ }^{4}$ In this issue of the Hong Kong Medical Journal, Lau et $\mathrm{al}^{5}$ have demonstrated the benefit of physiotherapistdesigned aquatic exercise in terms of physical and psychosocial functioning.

Surgery for total knee replacement (TKR) is indicated for end-stage knee arthritis and failed conservative treatment. Total knee replacement is a very effective treatment for OA knee in terms of pain relief, improvement of function, and quality of life. Owing to advances in prosthesis design, surgical techniques, anaesthesia, and perioperative pain management regimens, patients undergoing TKR have a relatively more pleasant experience and faster recovery than in the past. It is a form of major surgery involving bone cuts and soft tissue dissection, in which postoperative pain control is very important both for the patient's comfort and to facilitate postoperative rehabilitation exercises. In this issue of the Journal, $\mathrm{Wu}$ and Wong ${ }^{6}$ showed how the different modes of postoperative analgesia method can benefit patients.

In a systematic review by Singh, ${ }^{7}$ the utilisation rate for TKR has increased over the last two to three decades and the demand will continue to increase in the years to come. In a study of trends from Swedish Register, the rates of primary TKR increased 5-fold over a 20-year period. ${ }^{8}$ A similar trend has also been observed in Hong Kong. The rising demand is related to the ageing of population, due to increased longevity and increasing acceptance for TKR by patients. The current demand for TKR has far outstripped the supply, and is reflected in the longer and longer waiting times in the public hospitals, where it is not uncommon for patients to wait a few years before receiving the procedure. This does not even take into account the waiting time between the referral and the first orthopaedic consultation.

Patients on the waiting list for TKR are usually in excruciating pain and have significant functional impairment. Some authors ${ }^{9-12}$ have suggested that long delays before surgery lead to deterioration in terms of pain, functionality, and health-related quality of life, which could eventually affect postsurgery outcomes. On the contrary, other studies have not revealed changes in pain control or selfreported physical function, regardless of the duration of the waiting list. ${ }^{13,14}$ In the latter studies, however, waiting periods were in general a few months only. There is no report on the impact of waiting time in terms of years, which is comparable to our current situation. Irrespective of whether or not protracted delay has a negative impact on outcomes, it is beyond doubt that delays cause physical, social, and emotional suffering to patients. In addition, there is a considerable social and emotional burden on their caretakers.

To alleviate this problem, the Hong Kong Government and the Hospital Authority have injected extra resources to establish two joint replacement centres, one in the Hong Kong Buddhist Hospital and the other in the Yan Chai Hospital. Highvolume joint replacement surgery can be performed in these specialised centres, which can deliver more efficient and cost-effective services. Following TKR moreover, high-volume hospital throughput appears to be negatively associated with mortality rates and positively associated with implant survivorship. ${ }^{15,16}$

Although the waiting times in Queen Elizabeth and Yan Chai hospitals have been markedly shortened, the two joint replacement 
centres cannot relieve the problem of long waiting list in other regional hospitals. Currently, patients can be referred from other hospitals to the joint replacement centres to facilitate earlier surgery. However, some patients refuse to have surgery in an unfamiliar setting, preferring to attend their own nearby regional hospitals with their familiar and trustworthy orthopaedic surgeons. On the other hand, the capacity of the two joint replacement centres are about to be saturated. To relieve the suffering of this group of patients, allocation of extra resources to hospitals with long waiting list queues is urgently needed.

Undoubtedly, our public health care system is facing more and more challenges from a variety of degenerative diseases associated with ageing; OA of knee is just one. The current public health care service is heavily subsidised by the Government, and the public always complain about the long waiting time for medical services in public hospitals. It is therefore foreseeable that the present health care model will not be sustainable. Health care reform is therefore an imperative, if Hong Kong inhabitants are to acquire an accessible and affordable quality health care service for the future.

\section{References}

1. Hong Kong Population Projections 2010-2039. Hong Kong: Census and Statistics Department.

2. Felson DT, Nevitt MC, Zhang Y, et al. High prevalence of lateral knee osteoarthritis in Beijing Chinese compared with Framingham Caucasian subjects. Arthritis Rheum 2002;46:1217-22.

3. Zhang $\mathrm{Y}, \mathrm{Xu} \mathrm{L}, \mathrm{Nevitt} \mathrm{MC}$, et al. Comparison of the prevalence of knee osteoarthritis between the elderly Chinese population in Beijing and whites in the United States: The Beijing Osteoarthritis Study. Arthritis Rheum 2001;44:2065-71.

4. American Academy of Orthopaedic Surgeons clinical practice guideline on treatment of osteoarthritis of the knee. 2nd ed. Rosemont (IL): American Academy of Orthopaedic Surgeons (AAOS); 2013 May 18.

5. Lau MC, Lam JK, Siu E, Fung CS, Li KT, Lam MW. Physiotherapist-designed aquatic exercise programme for community-dwelling elders with osteoarthritis of the knee: a Hong Kong pilot study. Hong Kong Med J 2014;20:16-23.

6. Wu JW, Wong YC. Elective unilateral total knee replacement using continuous femoral nerve blockade versus conventional patient-controlled analgesia: peri-operative patient management based on a multidisciplinary pathway. Hong Kong Med J 2014;20:45-51.

7. Singh JA. Epidemiology of knee and hip arthroplasty: a systematic review. Open Orthop J 2011;5:80-5.

8. Robertsson O, Dunbar MJ, Knutson K, Lidgren L. Past incidence and future demand for knee arthroplasty in Sweden: a report from the Swedish Knee Arthroplasty Register regarding the effect of past and future population changes on the number of arthroplasties performed . Acta Orthop Scand 2000;71:376-80.

9. Fortin PR, Penrod JR, Clarke AE, et al. Timing of total joint replacement affects clinical outcomes among patients with osteoarthritis of the hip or knee. Arthritis Rheum 2002;46:3327-30.

10. Hoogeboom TJ, van den Ende CH, van der Sluis G, et al. The impact of waiting for total joint replacement on pain and functional status: a systematic review. Osteoarthritis Cartilage 2009;17:1420-7.

11. Desmeules F, Dionne CE, Belzile ÉL, Bourbonnais R, Frémont $\mathrm{P}$. The impacts of pre-surgery wait for total knee replacement on pain, function and health-related quality of life six months after surgery. J Eval Clin Pract 2012;18:11120.

12. Ahmad I, Konduru S. Change in functional status of patients whilst awaiting primary total knee arthroplasty. Surgeon 2007;5:266-7.

13. Kelly KD, Voaklander DC, Johnston DW, Newman SC, Suarez-Almazor ME. Change in pain and function while waiting for major joint arthroplasty. J Arthroplasty 2001;16:351-9.

14. Kelly KD, Voaklander D, Kramer G, Johnston DW, Redfern L, Suarez-Almazor ME. The impact of health status on waiting time for major joint arthroplasty. J Arthroplasty 2000;15:877-83.

15. Manley M, Ong K, Lau E, Kurtz SM. Total knee arthroplasty survivorship in the United States Medicare population: effect of hospital and surgeon procedure volume. J Athroplasty 2009;24:1061-7.

16. Hervey SL, Purves HR, Guller U, Toth AP, Vail TP, Pietrobon R. Provider Volume of Total Knee Arthroplasties and Patient Outcomes in the HCUP-Nationwide Inpatient Sample. J Bone Joint Surg Am 2003;85-A:1775-83. 